\title{
Determinação de unidades morfolitológicas da Bacia do Rio Itu - oeste do Rio Grande do Sul ${ }^{*}$
}

\author{
Romario Trentin ${ }^{* *}$ \\ Luís Eduardo de Souza Robaina ${ }^{* * *}$
}

\section{Resumo}

Este trabalho apresenta estudos e mapeamento das unidades morfolitológicas que ocorrem na bacia do rio Itu, oeste do Rio Grande do Sul, Brasil. O método de trabalho se baseou na identificação das características do relevo através de sua análise topográfica e da rede de drenagem. O mapa litológico apresentou os tipos de rochas encontradas na bacia hidrográfica e os principais controles estruturais definindo cinco grandes blocos. As nove unidades morfolitológicas foram definidas com o cruzamento das informações do relevo e substrato geológico onde cada unidade apresenta comportamentos diferentes em relação aos processos de dinâmica superficial.

Palavras-chave: Bacia Hidrográfica; Unidades Morfolitológicas; Oeste do RS.

Morpholithological units determination in the Itu River Basin - west part of the state of Rio Grande do Sul

\begin{abstract}
The following paper aims at presenting studies and mappings of the morpholitological units of the basin of the Itu River, which lies in the west of the state of Rio Grande do Sul,

* Trabalho realizado com apoio FAPERGS sob processo $n^{\circ}$ 05/1812.3.

** Universidade Federal de Santa Maria (tocogeo@yahoo.com.br).

*** Universidade Federal de Santa Maria (lesro@hanoi.base.ufsm.br).
\end{abstract}

Geosul, Florianópolis, v. 23, n. 46, p 163-183, jul./dez. 2008 
TRENTIN, R. \& ROBAIMA, L.E.S. Determinação de unidades ...

Brazil. The working approach was based on the landscape characteristics identification and the analysis of topography and drainage system. The lithological map presents the types of rocks found in the hydrographic basin and the main structural control, defining five big blocks. The nine morpholitological units were defined through the comparison of landscape and geological substrate where each unit presents different responses to the processes of superficial dynamics.

Key words: Hydrographic Basin; Morpholitological Units; West of the state of Rio Grande do Sul.

\section{Introdução}

O sistema natural é composto de vários elementos que desencadeiam os processos que agem na modificação do relevo. Estes elementos desenvolvem a esculturação do relevo, modificando-o constantemente, na forma de processo de retroalimentação, com entrada e saída de energia, característico de um sistema aberto.

Este trabalho desenvolve o levantamento das características da rede de drenagem, do relevo e das litologias na bacia hidrográfica do rio Itu, definindo unidades morfolitológicas homogêneas.

No Rio Grande do Sul, nas regiões Sudoeste e Oeste, o tema degradação ambiental ganha significativa importância na medida em que o estudo destas áreas vem ao encontro de uma das mais significativas preocupações ecológicas no Estado que é a recuperação, ou ao menos a amenização dos processos de erosão acelerados e arenização. Os dados cartográficos em escalas maiores são pouco disponíveis, e por isso o entendimento do desenvolvimento dos processos de dinâmica superficial ainda necessita ser investigado.

Suertegaray (1987), considera que o sudoeste do Rio Grande do Sul apresenta grande fragilidade na paisagem e trata da a problemática desta área. Suertegaray et al. (2001) elaboraram um 
TRENTIN, R. \& ROBAIMA, L.E.S. Determinação de unidades ...

Atlas, onde procuram mapear as principais áreas de arenização e levantar dados sobre algumas bacias hidrográficas da região. Suertegaray (1992) tem uma importante contribuição, na publicação do livro "Deserto Grande do Sul: Controvérsias", tratando da problemática da arenização da região.

Souto (1985) nas décadas de 60 e 70, verificou um estímulo governamental acentuado, através de linhas de créditos, para atividades agropecuárias, e esta atividade veio a acentuar os processos de dinâmica superficial no oeste do Rio Grande do Sul.

Além destes trabalhos, outros podem ser citados, abordando diversos enfoques da dinâmica superficial do oeste do Rio Grande do Sul. Entre eles pode-se destacar:

Verdum (1993; 1997), em trabalhos de mestrado e doutoramento fez uma abordagem de paisagem na região dos municípios de São Francisco de Assis e Manuel Viana.

$\mathrm{Na}$ linha de mapeamentos e análises morfométricas, cita-se o Laboratório de Geologia Ambiental (LAGEOLAM/UFSM), que tem desenvolvido trabalhos nesta área.

A constatação mais evidente oriunda destas observações é a de que zonas marcadas por grande susceptibilidade à dinâmica superficial, como as registradas no oeste do Rio Grande do Sul, apresentam significativa relação com as litologias da área.

Os mapas e informações dos substratos rochosos são levantamentos básicos para a análise do meio e das formas de ocupação, além de serem indispensáveis na realização dos mapeamentos geoambientais.

O rio Itu é afluente da margem direita do rio Ibicuí e localiza-se no oeste do Rio Grande do Sul, estendendo-se pelos municípios de São Francisco de Assis, Manuel Viana, Itaquí, Unistalda, Maçambará, São Borja e Santiago. Com uma área de $2.809,6 \mathrm{~km}^{2}$, esta bacia hidrográfica está inserida entre as coordenadas geográficas $54^{\circ} 52^{\prime} 20^{\prime \prime}$ a $55^{\circ} 53^{\prime} 15^{\prime}$ " de longitude oeste e $28^{\circ} 58^{\prime} 00^{\prime \prime}$ a $29^{\circ} 24^{\prime} 40^{\prime}$ de latitude sul (Figura 01).

$\mathrm{O}$ estudo da bacia do rio Itu representa mais um conjunto de informações que tem sido gerado pelo Laboratório de Geologia 
TRENTIN, R. \& ROBAIMA, L.E.S. Determinação de unidades ...

Ambiental (LAGEOLAM/UFSM) sobre a região oeste do estado do RS.

\section{Metodologia}

As cartas base para o estudo da rede hidrográfica e do relevo foram às cartas topográficas em escala 1:50.000 da Divisão de Levantamento do Exército(DSG). A Figura 02 mostra o fluxograma metodológico utilizado para a elaboração do trabalho.

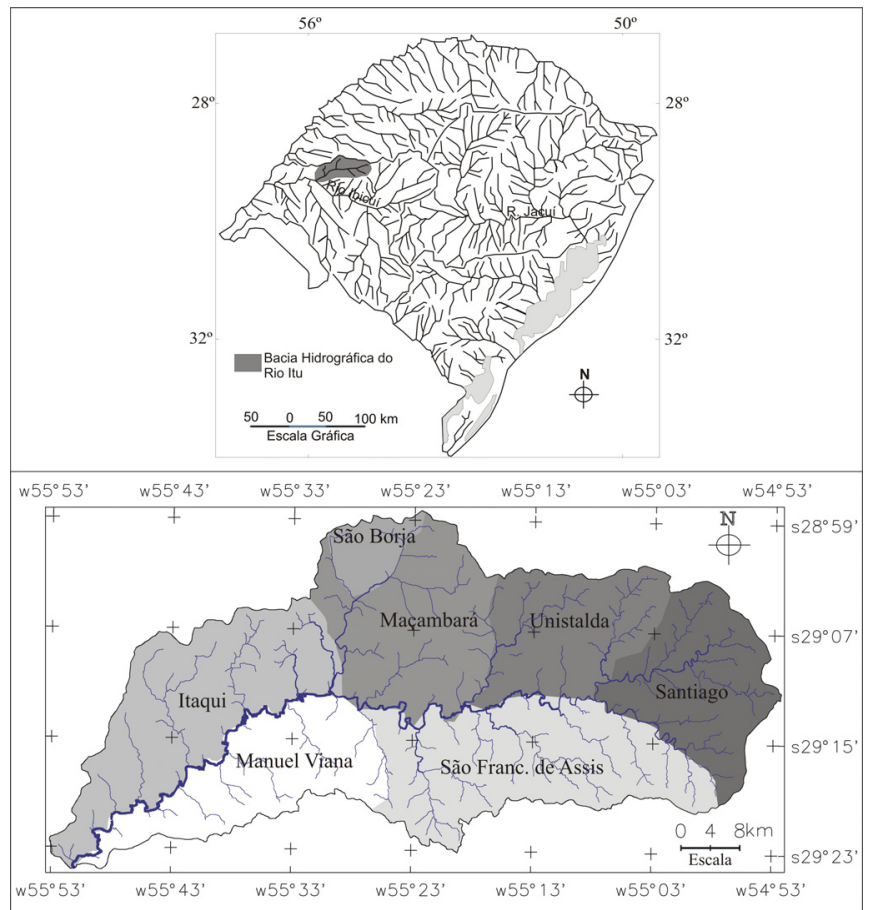

Figura 01: Mapa de localização da área de estudo

Os atributos da rede hidrográfica como a área, perímetro, magnitude, ordem, padrão dos cursos d'água e densidade de drenagem (relação entre o comprimento total dos canais de 
TRENTIN, R. \& ROBAIMA, L.E.S. Determinação de unidades ...

escoamento e a área total da bacia), foram analisados usando como base às classificações de Strahler e Horton (apud CHRISTOFOLETTI, 1974).

$\mathrm{O}$ estudo do relevo foi baseado nos atributos referentes à declividade, altitude, amplitude e comprimento de vertentes. Para a elaboração do mapa de declividade da bacia hidrográfica utilizaramse três limites de declividade, constituindo quatro classes: $<2 \% ; 2$ a $5 \% ; 5$ a $15 \%$ e $>15 \%$, que foram adaptados do Instituto de Pesquisas Tecnológicas do estado de São Paulo (IPT, 1981).

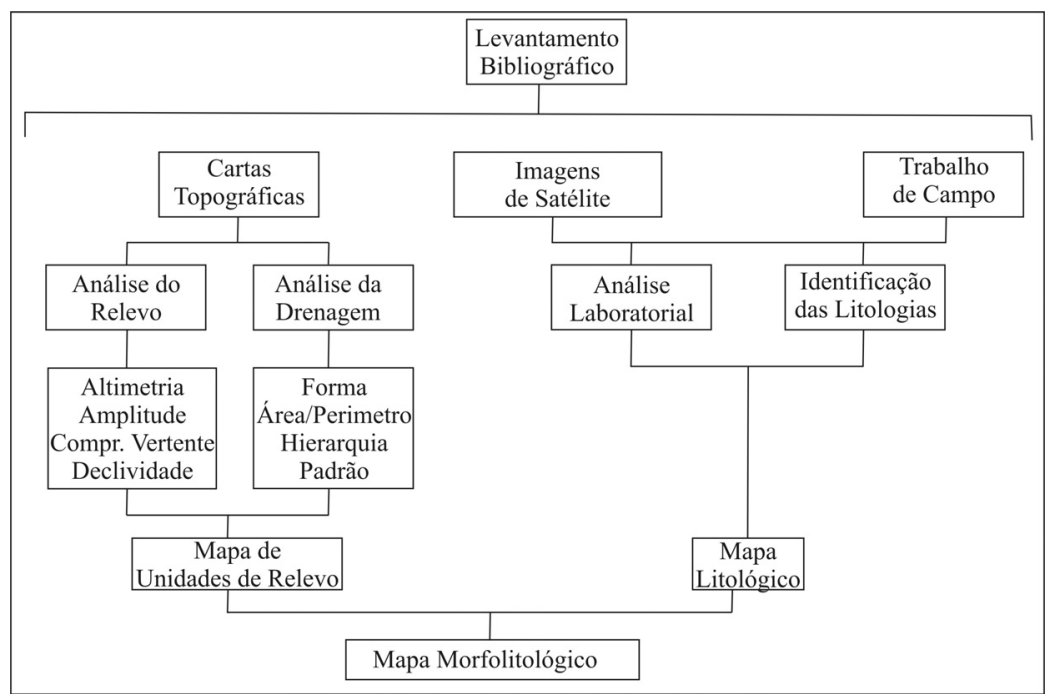

Figura 02: Fluxograma metodológico

Como ferramenta de apoio foi feita a análise e classificação digital das imagens de satélite LANDSAT 7 ETM+ e CBERS. Os trabalhos de campo utilizando-se o levantamento de perfis permitiram o reconhecimento das litológicas e confirmando as identificações realizadas através das imagens de satélite. Nesses trabalhos foram analisados "in loco" os afloramentos de rochas e contatos entre os diferentes copos de rochas vulcânico 
TRENTIN, R. \& ROBAIMA, L.E.S. Determinação de unidades ...

identificados na área, bem como dos contatos entre as diferentes litologias.

A avaliação da área e definição das unidades se deu a partir da técnica de mapeamento geoambiental do Laboratório de Geologia Ambiental (LAGEOLAM/UFSM) (Trentin e Robaina, 2005), que baseia-se na possibilidade de divisão da área estudada em unidades homogêneas.A atividade iniciou pela construção de mapas temáticos da rede de drenagem, relevo e litologias. A análise em conjunto desses atributos através da sobreposição das cartas permitiu definir as unidades morfolitológicas.

Para a elaboração dos mapas e interpolação dos dados, utilizou-se o software Spring 4.2 desenvolvido pelo Instituto Nacional de Pesquisas Espaciais (INPE) e Corel DRAW 12, desenvolvido pela Corel Inc.

\section{Discussão dos resultados}

Sobre uma contextualização geomorfológica, a área de estudo, conforme classificação de Chebataroff (1954, apud MULLER FILHO, 1970), a bacia hidrográfica insere-se em três compartimentos, a Depressão Periférica do Rio Grande do Sul, o Rebordo do Planalto e o Planalto sul-rio-grandense. Isso reflete nas suas principais características quanto à rede de drenagem, as formas de relevo e litologias presentes.

\section{Análise da rede de drenagem}

A área da bacia hidrográfica é de cerca de $2.809,6 \mathrm{~km}^{2} \mathrm{com}$ um perímetro de 328,79 quilômetros, representando uma das mais importantes bacias afluentes do rio Ibicuí.

O índice de circularidade é de 0,32 representando uma bacia com baixa circularidade e com importante controle estrutural. Esse controle de falhas e fraturas está refletido no padrão de drenagem predominantemente do tipo retangular-dendrítico.

A bacia do rio Itu apresenta uma hierarquia fluvial de $7^{\text {a }}$ ordem e estende-se E-W por $116.45 \mathrm{~km}$ quando ocorre uma inflexão para o sul, NE-SW por mais $83.9 \mathrm{~km}$, até sua foz, junto ao 
TRENTIN, R. \& ROBAIMA, L.E.S. Determinação de unidades ...

rio Ibicui. Seus principais afluentes na margem direita da nascente para a foz são: Arroio Lagoão, Arroio Porteirinha, Arroio ItuMirim, Sanga do Narciso, Arroio Puitã, Sanga Restinga das Cascatas, Arroio Restinga dos Pires, Arroio Curuçu e Sanga do Barreiro. Os da margem esquerda são: Arroio Ituzinho, Sanga Águas Claras, Sanga da Santa Rosa, Arroio Passarinho, Sanga do Lageado, Sanga do Herval e Sanga do Helói.

A bacia foi dividida em três setores: setor A, correspondendo à porção do alto curso da bacia hidrográfica; o setor $\mathrm{B}$, correspondendo ao médio curso da bacia hidrográfica; o setor C porção do baixo curso da bacia hidrográfica, Figura 03.

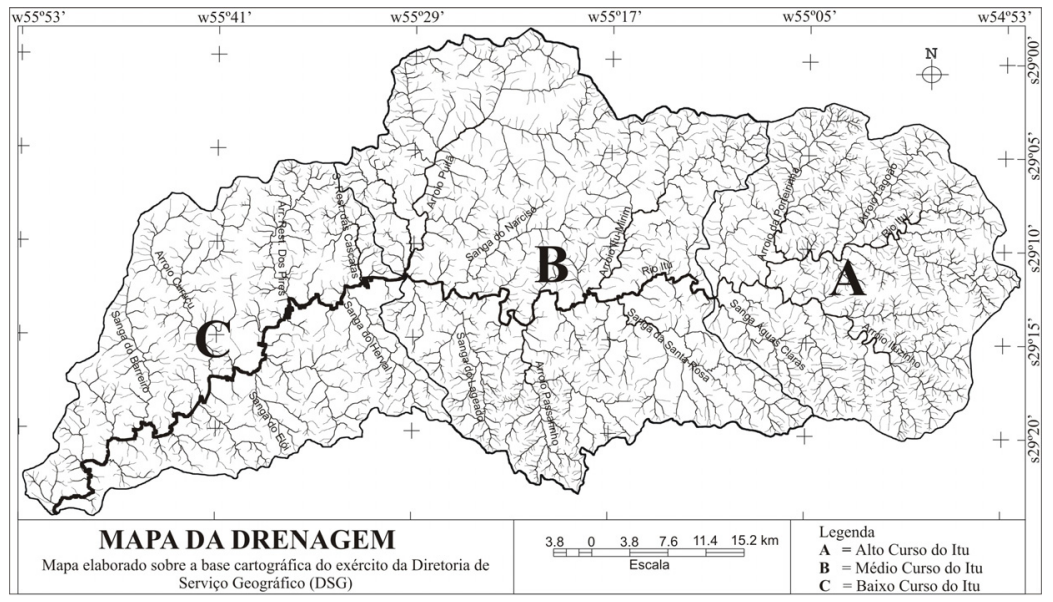

Figura 03: Mapa dos setores da drenagem da bacia do Rio Itu

O setor A possui uma área de $720,35 \mathrm{~km}^{2}$ e se estende desde o município de Santiago, topo do planalto até o o canal principal adquirir a hierarquia de $6^{\mathrm{a}}$ (sexta) ordem, pela confluência da Sanga Águas Claras com o Rio Itu. Apresenta uma densidade de drenagem de $2,0 \mathrm{~km} / \mathrm{km}^{2}$.

O setor B se refere ao médio curso da bacia hidrográfica, com área de $1.259,12 \mathrm{~km}^{2}$ estende-se desde o local em que o Rio Itu se torna de $6^{\mathrm{a}}$ ordem, até onde o canal principal adquire a 
TRENTIN, R. \& ROBAIMA, L.E.S. Determinação de unidades ...

hierarquia de $7^{\mathrm{a}}$ ordem, com a confluência do arroio Puitã. A drenagem neste setor apresenta um comprimento total de 2.176,68 quilômetros, condicionando uma densidade de drenagem de 1,7 $\mathrm{km} / \mathrm{km}^{2}$.

$\mathrm{O}$ setor $\mathrm{C}$ se apresenta a partir da porção em que o canal principal adquire a hierarquia de $7^{\mathrm{a}}$ ordem, e estende-se até desaguar no Rio Ibicuí. Este setor apresenta uma inflexão para sul, em relação ao restante da bacia hidrográfica, com o canal principal passando a ter seu percurso nordeste-sudoeste, obedecendo a linha de falhamentos predominantes da área de estudo. A área deste setor é de $830,09 \mathrm{~km}^{2}$, e o comprimento total da drenagem é de $1.255,36$ quilômetros, o que gera uma densidade de drenagem de 1,5 $\mathrm{km} / \mathrm{km}^{2}$.

\section{Análise do relevo}

Os atributos identificados permitiram a individualização de sete unidades com características homogêneas de relevo, representadas no Quadro 01 e identificadas na Figura 04.

A primeira unidade se apresenta com declividades inferiores a $2 \%$, e altitudes que não ultrapassam os 80 metros. Esta unidade está localizada no baixo curso da bacia hidrográfica junto ao canal principal próximo a sua foz, no Ibicuí, e outra, junto ao canal principal, próxima ao médio curso. Ocupa uma área de $87,42 \mathrm{~km}^{2}$, ou seja, $3,11 \%$ da área total da bacia.

A segunda unidade é definida por relevo suavemente ondulado com altitudes variando entre 80 a 200 metros. Esta unidade ocupa uma grande área junto ao médio curso da bacia hidrográfica. Corresponde a $475,50 \mathrm{~km}^{2}$, representando $16,92 \%$ da área total. Constituem as áreas de interflúvios no baixo curso da bacia hidrográfica e ocorrem também, junto aos cursos de importantes afluentes do Itu, no médio curso.

$\mathrm{Na}$ terceira unidade as vertentes são onduladas, com declividades de 5 a $15 \%$ e altitudes inferiores a 200 metros. Ocupa a maior área na bacia do Rio Itu, com $1156,18 \mathrm{~km}^{2}$, o que 
TRENTIN, R. \& ROBAIMA, L.E.S. Determinação de unidades ...

corresponde a $41,15 \%$ da área total, e está localizada de forma esparsa pelos três setores da bacia hidrográfica.

A quarta unidade é definida por vertentes onduladas, com declividades entre 5 e $15 \%$, e altitudes superiores a 200 metros. Esta unidade distribui-se por toda a bacia hidrográfica, e ocupa uma área de $286,64 \mathrm{~km}^{2}$, ou seja, $10,05 \%$ da área total.

$\mathrm{Na}$ quinta unidade ocorrem vertentes onduladas a fortemente onduladas e altitudes inferiores a 200 metros. Ocupa principalmente uma faixa central da bacia hidrográfica que se estende de norte a sul, pertencendo ao setor B (médio curso) e possui $234,11 \mathrm{~km}^{2}$, corresponde a $8,33 \%$ da área total da bacia.

Quadro 01: Características das unidades de relevo da bacia hidrográfica do Rio Itu

\begin{tabular}{|c|c|c|c|c|}
\hline $\begin{array}{l}\text { Unidades } \\
\text { definidas }\end{array}$ & $\begin{array}{c}\text { Declividade } \\
(\%)\end{array}$ & $\begin{array}{c}\text { Altitude } \\
\text { (m) }\end{array}$ & $\begin{array}{l}\text { Características } \\
\text { Predominantes }\end{array}$ & $\begin{array}{c}\text { \% da Área } \\
\text { total }\end{array}$ \\
\hline I & $<2$ & $<80$ & Áreas Planas & 3,11 \\
\hline II & $<5$ & $80-200$ & Suavemente Onduladas & 16,92 \\
\hline III & \multirow{2}{*}{$5-15$} & $<200$ & \multirow{2}{*}{ Onduladas } & 41,15 \\
\hline IV & & $>200$ & & 10,05 \\
\hline $\mathrm{V}$ & \multirow{3}{*}{$>15$} & $<200$ & \multirow{2}{*}{ Fortemente Ondulada } & 8,33 \\
\hline VI & & $>200$ & & 15,45 \\
\hline VII & & $>200$ & Escarpa & 7,06 \\
\hline
\end{tabular}

A sexta unidade caracteriza-se por suas declividades predominantes superiores a $15 \%$, com vertentes fortemente onduladas e altitudes superiores a 200 metros. Esta encontra-se inserida principalmente no setor A (alto curso) com pequenas áreas no setor B (médio curso), ocupando a maior parte do alto curso da bacia hidrográfica, e ainda pequenas áreas junto ao divisor d'água do médio curso. Esta unidade ocupa uma área de $448.21 \mathrm{~km}^{2}$, o que corresponde a $15,45 \%$ da área total da bacia hidrográfica.

A sétima unidade está associada à anterior formada por vertentes em forma de escarpas, com declividades superiores a $15 \%$. Esta é definida no setor A junto ao rebordo do planalto onde as 
TRENTIN, R. \& ROBAIMA, L.E.S. Determinação de unidades ...

vertentes associadas aos cursos d'água tornam-se escarpados com altas declividades, e no médio curso, setor $\mathrm{B}$, associados ao divisor d'água da margem direita do Rio Itu. Esta unidade ocupa uma área de $121,51 \mathrm{~km}^{2}$, ou seja, 7,06\% do total da bacia do Rio Itu.

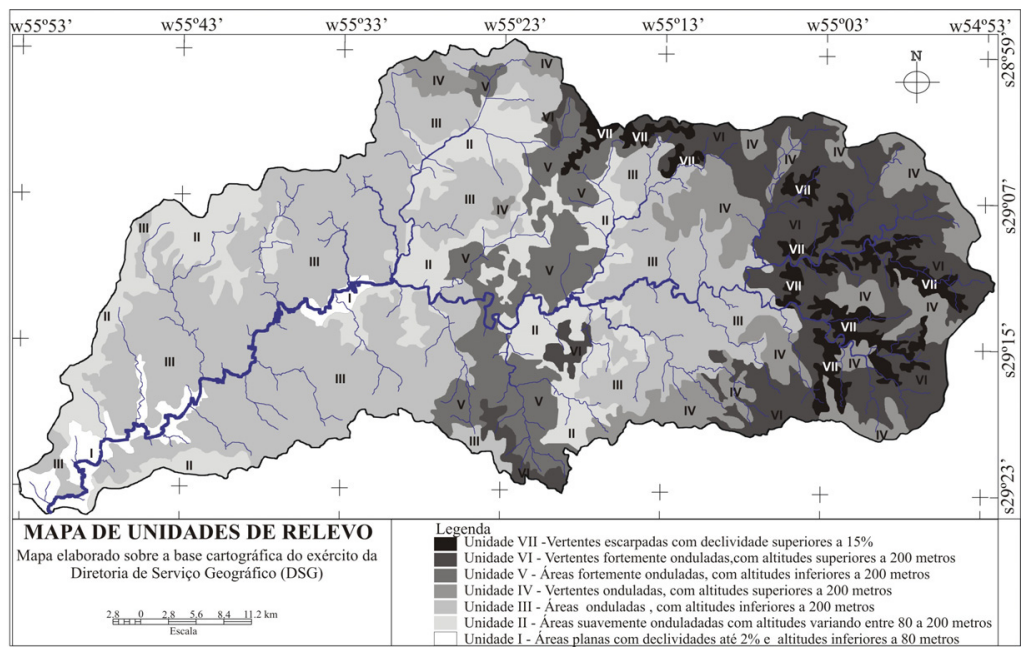

Figura 04: Mapa de unidades de relevo da bacia do Rio Itu

\section{Unidades litológicas}

A bacia hidrográfica do Rio Itu foi dividida em cinco blocos, individualizados através de falhamentos que marcam a movimentação tectônica entre esses blocos. A dinâmica da esculturação da topografia e controle da rede de drenagem tem forte interferência da tectônica de falhamentos da área. As litologias compreendem depósitos recentes do Rio Itu e rochas vulcânicas e sedimentares da Bacia do Paraná (TRENTIN e ROBAINA, 2006).

Os depósitos recentes estão representados por depósitos aluviais. Na porção do médio curso do rio Itu, os depósitos são de cascalho e blocos predominantemente de rochas vulcânicas. Os sedimentos no baixo curso são constituídos principalmente de 
TRENTIN, R. \& ROBAIMA, L.E.S. Determinação de unidades ...

areias que estão sendo retrabalhadas, moderadamente classificadas, formando pequena planície de inundação.

As rochas vulcânicas são encontradas na Formação Serra Geral, representadas por derrames vulcânicos que ocorreram no Sul do Brasil. Esses não apresentam uma continuidade uniforme, estando intercalados com as formações sedimentares.

Os trabalhos definiram na bacia hidrográfica um total de seis derrames, ocorrendo, algumas vezes, a presença de arenitos intertrápicos.

Em nível abaixo das rochas vulcânicas e por vezes intercalado ocorrem arenitos bem classificados, avermelhados (por vezes róseos a esbranquiçados) de granulação fina a média, com grãos bem selecionados e bem arredondados, em geral foscos e apresentando alta esfericidade. A estrutura predominante é de estratos cruzados de alto ângulo formando "sets" bastante longos.

As características permitem definir como rochas pertencentes à Formação Botucatu, representando dunas de origem eólica.

A superfície de contato entre as formações Botucatu e Serra Geral, não constituem um plano uniforme, mas apresenta ondulações e inclinação que dificultam definir um plano de contato na área.

O terceiro substrato litológico, colocado estratigraficamente abaixo do Botucatu, caracteriza-se por sua textura areia com grânulos de quartzo e calcedônia dispersos, estrutura por vezes bem definida, de estratos cruzados acanalados e planares com "sets" curtos e médios, e plano-paralelas, indicando, junto a outras feições, um ambiente deposicional de características fluviais. A mineralogia é de quartzo tanto na fração areia, quanto na fração grossa. Nesta, os clastos variam desde $2 \mathrm{~mm}$ até cerca de 2 a $3 \mathrm{~cm}$, predominantemente de quartzo leitoso. Em alguns afloramentos são encontrados de maneira esparsa, conglomerados intraformacionais constituídos por clastos argilosos róseos, com até $10 \mathrm{~cm}$ de eixo maior. A cimentação de óxido de ferro quando preenche espaços dos poros confere maior resistência aos arenitos. 
TRENTIN, R. \& ROBAIMA, L.E.S. Determinação de unidades ...

Junto às linhas de falhas estes arenitos aparecem silicificados, o que os torna mais resistentes aos processos da dinâmica superficial. Nestas condições ocorrem sob a forma de afloramentos de blocos na meia encosta, formando "degrau" no relevo e morrotes, conhecidos regionalmente como cerros.

Com base em Scherer et al. (2002), essa seqüência sedimentar de origem fluvial, foi definida como pertente à Formação Guará de idade Mesozóica, Jurássico Superior/Cretáceo Inferior.

O mapa da Figura 05 apresenta as litologias presentes na bacia do Rio Itu, e são mostradas através de croquis explicativos.

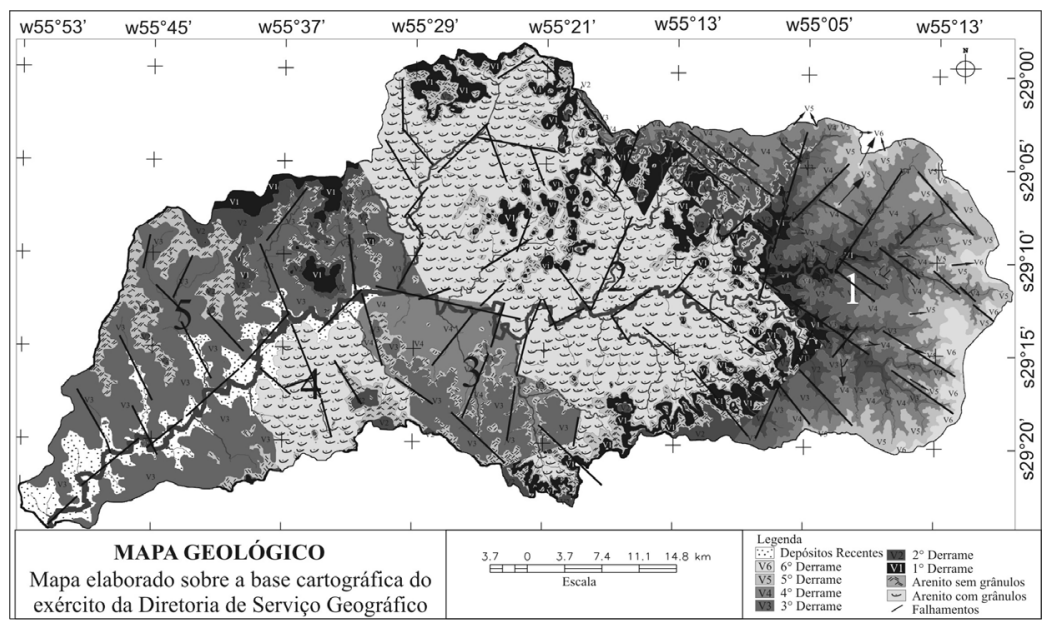

Figura 05: Mapa litológico da bacia do Rio Itu

O croqui 1 mostra a distribuição das litologias do bloco 1 , em seis pacotes de rochas vulcânicas sendo isso devido a terem sido originadas por diferentes derrames vulcânicos na bacia hidrográficas. São observados neste, contatos diretos entre diferentes pacotes de rochas vulcânicas, e ainda a presença de camadas de arenitos sem grânulos (Formação Botucatu) intercalando-se com os pacotes de rochas vulcânicas. 
TRENTIN, R. \& ROBAIMA, L.E.S. Determinação de unidades ...

O croqui 2 mostra a distribuição das litologias do bloco 2, onde são identificados apenas dois pacotes de rocha vulcânica com camadas de arenitos sem grânulos (Formação Botucatu) intercalando-se com as rochas vulcânicas e sob estes a presença de arenito com grânulos (Formação Guará).

$\mathrm{O}$ croqui 3 mostra a distribuição das litologias do bloco 3 onde são observados apenas a presença de rochas vulcânicas com arenitos sem grânulos (Formação Botucatu) intercalados e a presença de depósitos recentes.

O croqui 4 mostra a distribuição das litologias do bloco 4 , onde se observa a presença do arenito com grânulos (Formação Guará), arenito sem granulo (Formação Botucatu), rocha vulcânica e a presença de depósitos recentes.

O croqui 5 mostra a distribuição das litologias do bloco 5 , onde se observa a presença de rocha vulcânica intercalada com os arenitos sem grânulos (Formação Botucatu) e a presença de depósitos recentes.

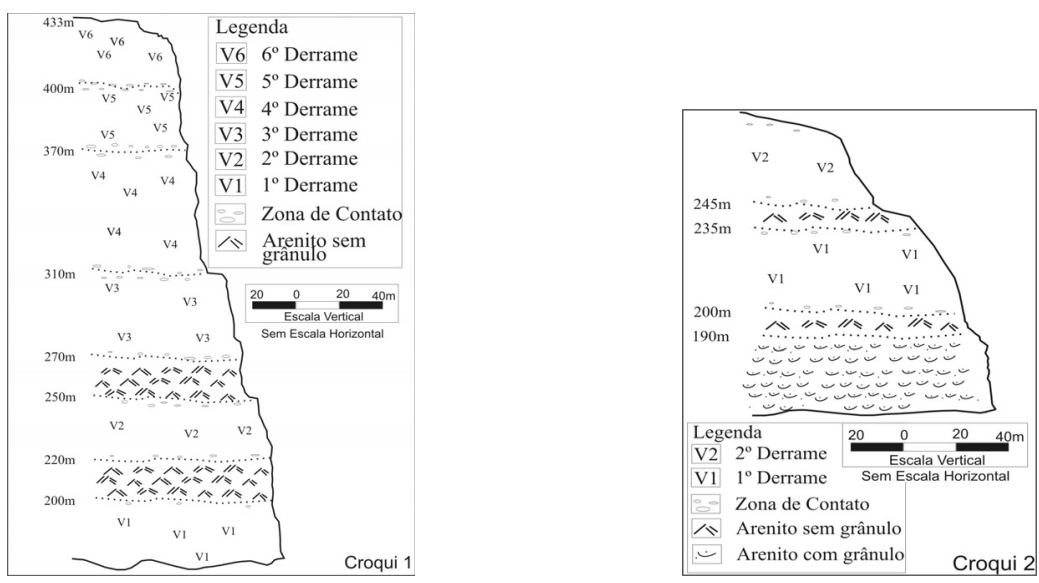

Croquis das litologias encontradas nos Blocos 1 e 2 respectivamente 
TRENTIN, R. \& ROBAIMA, L.E.S. Determinação de unidades ...
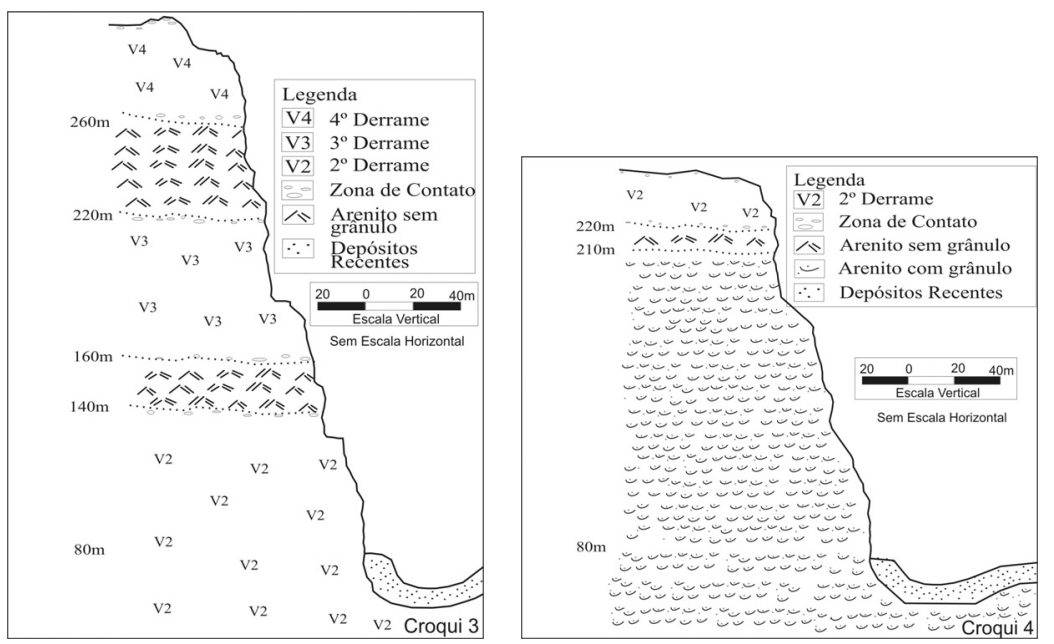

Croquis das litologias encontradas nos Blocos 3 e 4 respectivamente

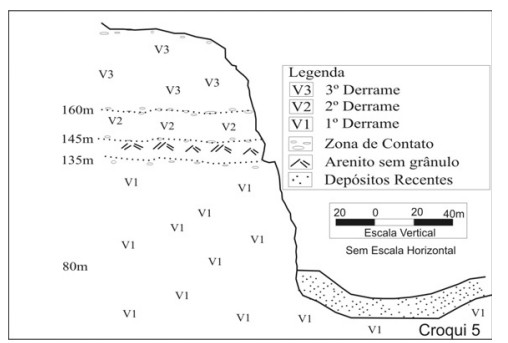

Croqui das litologias encontradas no Bloco 5

\section{Compartimentação morfolitológica}

A análise das características da rede de drenagem, do relevo e do substrato litológico permitiram definir unidades da bacia com comportamento semelhante, principalmente frente aos processos de dinâmica superficial. Os dados obtidos possibilitaram a compartimentação da bacia do Rio Itu que está apresentada cartograficamente na Figura 06 e esquematicamente no Quadro 02. Os estudos identificaram 09 unidades definidas por seus atributos. 
TRENTIN, R. \& ROBAIMA, L.E.S. Determinação de unidades ...

Unidade I - Apresenta declividades inferiores a $2 \%$, e altitudes que não ultrapassam os 80 metros. Os processos de dinâmica superficial geram acumulação de sedimentos. Os sedimentos são constituídos principalmente de areias que estão sendo retrabalhadas, moderadamente classificadas.

Na planície de inundação ocorrem os depósitos mais finos constituídos de silte a argila.

Unidade II - Constitui as áreas suavemente onduladas junto ao divisor d'água do rio Itu, próximo à sua foz. Formada por rochas vulcânicas representando o primeiro e o segundo derrame com arenitos intertrápicos. Os processos de dinâmica superficiais associado à erosão são de baixa intensidade, ocorrendo apenas pequenos ravinamentos. A meteorização é mais significativa no topo das colinas e o tipo e espessura do solo depende da porção do derrame que está sendo alterada. As porções próximas aos contatos tendem a formar solos mais desenvolvidos por sua maior alterabilidade e devido à concentração de água nesses locais.

Unidade III - Vertentes suavemente onduladas com altitudes variando entre 80 a 200 metros. Esta unidade ocupa uma grande área junto ao médio curso da bacia hidrográfica. O substrato é constituído de arenitos com grânulos, definidos como fluviais, e os processos erosivos são significativos, com ocorrência de voçorocas e areais (Figura 07). A topografia em forma de colinas favorece os processos de meteorização que sobre o substrato de arenitos friáveis gera perfis de alteração espessos e muito susceptíveis a processos erosivos. Os processos erosivos estão associados a cabeceiras de drenagem ou ligados a degraus compostos por arenitos silicificados na meia encosta.

Unidade IV - Vertentes onduladas, com declividades de 5 a $15 \%$ e altitudes inferiores a 200 metros. O substrato é constituído de rochas vulcânicas com espessura variando de $15 \mathrm{~m}$ a $60 \mathrm{~m}$. A espessura do solo varia de poucos centímetros até solos profundos, e a textura argilosa mantém a coesão não sendo significativos os processos erosivos. 
TRENTIN, R. \& ROBAIMA, L.E.S. Determinação de unidades ...

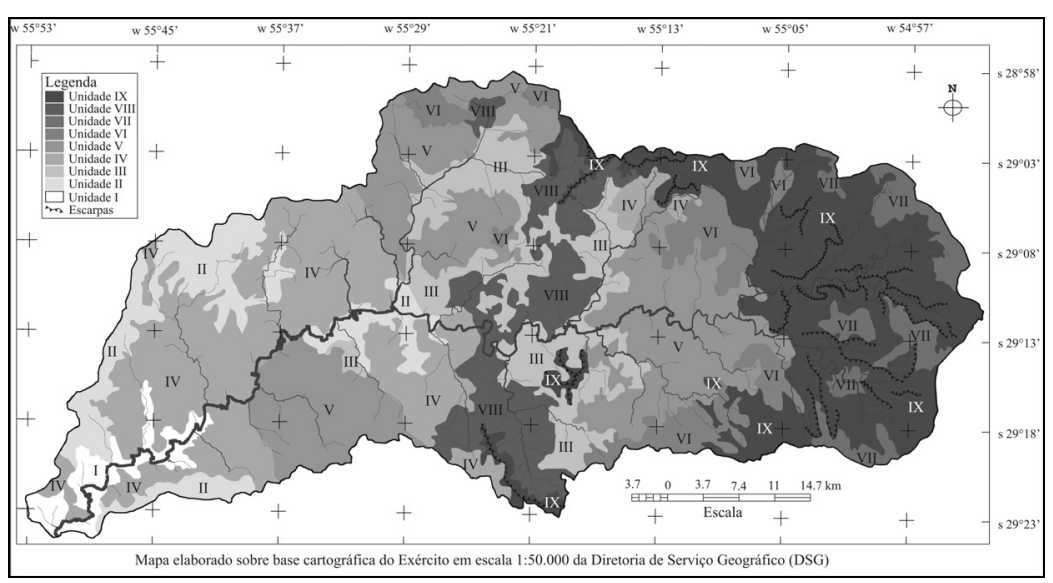

Figura 06: Mapa morfolitológico da bacia do Rio Itu.

Quadro02: Unidades Morfolitológicas da bacia do Rio Itu

\begin{tabular}{|c|c|c|c|c|c|}
\hline Unidades & $\begin{array}{c}\text { Declividade } \\
(\mathbf{\%})\end{array}$ & $\begin{array}{c}\text { Altitude } \\
(\mathbf{m})\end{array}$ & Morfologia & Substrato & $\begin{array}{c}\text { Principais proc. } \\
\text { dinâmica superficial }\end{array}$ \\
\hline I & $<2$ & $<80$ & Plana & Sedimentos & $\begin{array}{c}\text { Acumulação de } \\
\text { Sedimentos }\end{array}$ \\
\hline II & $<5$ & $<200$ & $\begin{array}{c}\text { Suavemente } \\
\text { Ondulada }\end{array}$ & $\begin{array}{c}\text { Vulcânica e } \\
\text { Arenito s/grânulos }\end{array}$ & $\begin{array}{c}\text { Processos de } \\
\text { Meteorização }\end{array}$ \\
\hline III & $<5$ & $80-200$ & $\begin{array}{c}\text { Suavemente } \\
\text { Ondulada }\end{array}$ & $\begin{array}{c}\text { Arenito friável } \\
\text { com grânulos }\end{array}$ & $\begin{array}{c}\text { Processos erosivos } \\
\text { avançados, areais e } \\
\text { voçorrocas }\end{array}$ \\
\hline IV & $5-15$ & $<200$ & Ondulada & Vulcânica & $\begin{array}{c}\text { Processos erosivos } \\
\text { moderados }\end{array}$ \\
\hline V & $5-15$ & $<200$ & Ondulada & $\begin{array}{c}\text { Arenito friável } \\
\text { com grânulos }\end{array}$ & $\begin{array}{c}\text { Processos erosivos c/ } \\
\text { geração de areais }\end{array}$ \\
\hline VI & $5-15$ & $>200$ & Ondulada & $\begin{array}{c}\text { Vulcânica e } \\
\text { Arenito s/grânulos }\end{array}$ & $\begin{array}{c}\text { Processos erosivos } \\
\text { moderados }\end{array}$ \\
\hline VII & $5-15$ & $>200$ & Ondulada & Vulcânica & $\begin{array}{c}\text { Processos erosivos } \\
\text { moderados }\end{array}$ \\
\hline VIII & $>15$ & $<200$ & $\begin{array}{c}\text { Ondulada a } \\
\text { Fortemente } \\
\text { Ondulada }\end{array}$ & $\begin{array}{c}\text { Arenito s/ } \\
\text { grânulos e } \\
\text { Vulcânica }\end{array}$ & $\begin{array}{c}\text { Processos erosivos } \\
\text { moderados e } \\
\text { movimento de massa }\end{array}$ \\
\hline IX & $>15$ & $>200$ & $\begin{array}{c}\text { Fortemente } \\
\text { Ondulada e } \\
\text { Escarpas }\end{array}$ & $\begin{array}{c}\text { Vulcânica e } \\
\text { Arenito s/ } \\
\text { grânulos }\end{array}$ & $\begin{array}{c}\text { Processos erosivos } \\
\text { rolamento de blocos, } \\
\text { escorregamentos } \\
\text { gerando degraus }\end{array}$ \\
\hline
\end{tabular}


TRENTIN, R. \& ROBAIMA, L.E.S. Determinação de unidades ...

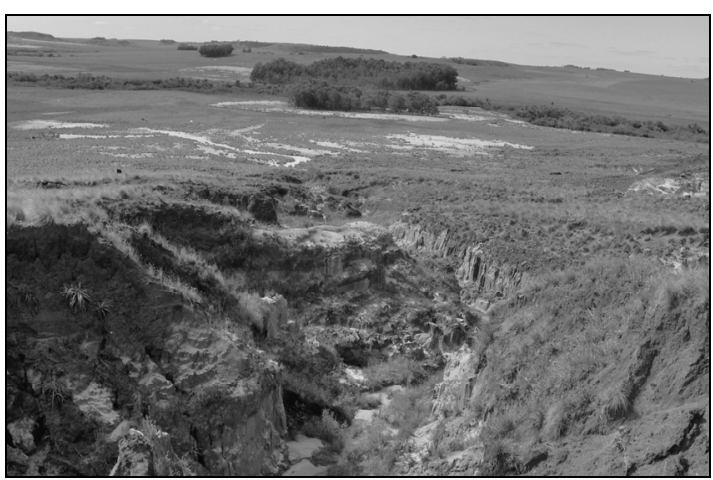

Figura 07: Na fotografia ficam evidenciados os resultados de processos erosivos gerando voçorocas na Unidade III

Unidade V - Vertentes onduladas, com declividades de 5 a $15 \%$ e altitudes inferiores a 200 metros. Substrato de arenitos friáveis com grânulos. Os solos gerados são muito susceptíveis a processos erosivos. Nesta unidade ocorrem as principais áreas de arenização (Figura 08). Os areais se desenvolvem a partir de desintegração das rochas arenosas com cimento ferruginoso, que devido à umidade do clima atual sofrem retrabalhamento e perdem a coesão se desintegrando. Os solos espessos muito friáveis não são resistentes à erosão.

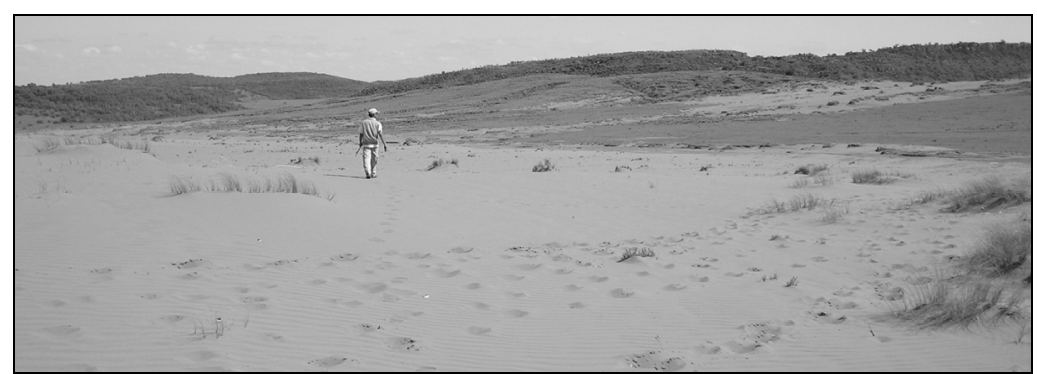

Figura 08: Fotografia mostrando areais na Unidade V

Unidade VI - Vertentes onduladas, com declividades entre 5 e $15 \%$, e altitudes superiores a 200 metros. Unidade do terreno 
TRENTIN, R. \& ROBAIMA, L.E.S. Determinação de unidades ...

com ocorrência de rochas vulcânicas associadas com rochas arenosas sem grânulos, bem classificadas. Processos erosivos são baixos, muitas vezes associados ao uso do solo.(Figura 09).

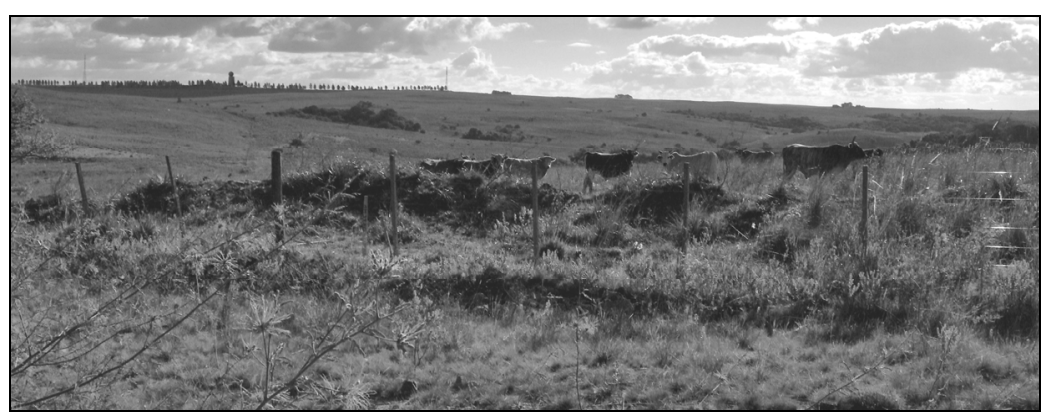

Figura 09: Fotografia mostrando a topografia ondulada em rocha vulcânica da Unidade VI

Unidade VII - Vertentes onduladas, com declividades entre 5 e $15 \%$, e altitudes superiores a 200 metros. Substrato vulcânico e os processos de dinâmica superficial são de baixa intensidade (Figura 10).

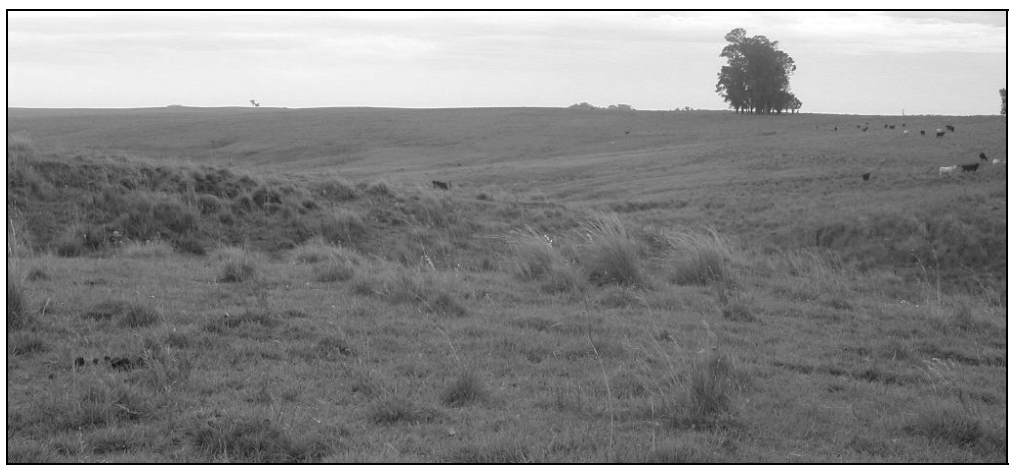

Figura 10: Fotografia mostrando a topografia ondulada da Unidade VII 
TRENTIN, R. \& ROBAIMA, L.E.S. Determinação de unidades ...

Unidade VIII - Vertentes onduladas a fortemente onduladas e altitudes inferiores a 200 metros. Formam morros e morrotes de arenitos com, algumas vezes, derrames no topo. Processos de dinâmica superficial relacionados à erosão e queda de blocos localizados. No contato entre esta unidade e as unidades de colinas de arenito (III) ocorrem, muitas vezes, processos erosivos acelerados pela troca brusca de comportamento frente à ação das águas pluviais.

Unidade IX - Declividades predominantes superiores a 15\%, com vertentes fortemente onduladas e escarpadas e altitudes superiores a 200 metros. Formam as vertentes do alto curso da bacia hidrográfica. Predomínio da exposição do $4^{\circ}, 3^{\circ}$ e $1^{\circ}$ derrames e ainda intercalações de arenito sem grânulos. Processos de dinâmica superficial relacionado ao escoamento superficial gerando erosão e movimentos de massa localizados, tombamento e queda de blocos (Figura 11).

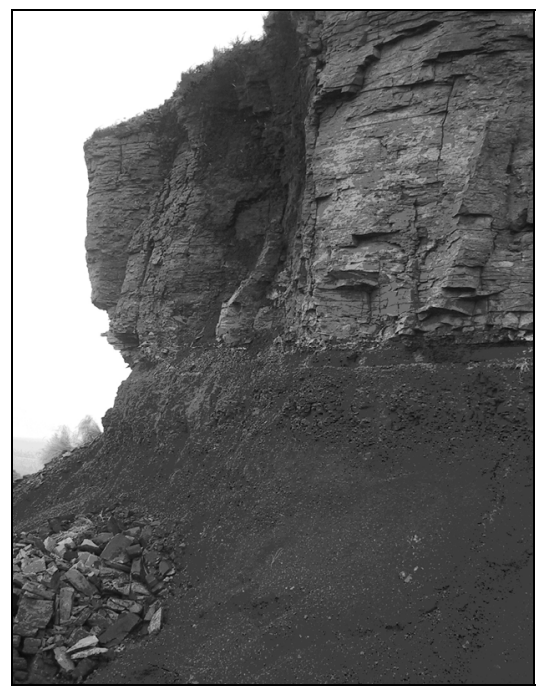

Figura 11: Fotografia mostrando a queda de blocos nas vertentes escarpadas da Unidade IX 


\section{Conclusões}

Uma bacia hidrográfica é uma porção de partes interconectadas que funcionam juntas como um todo complexo. Para compreender a dinâmica superficial em determinada área é preciso conhecer os atributos envolvidos nos processos.

A análise dos dados identificou 09 unidades morfolitológicas, o que demonstra a grande diversidade encontrada na bacia hidrográfica do Rio Itu, o que demonstra a grande importância de estudos desta natureza, para melhor compreensão das características da área e dos processos atuantes.

O mapa morfolitológico deve ser utilizado como ferramenta para ajudar a definir a ocupação e a fragilidade frente ao uso dos terrenos na bacia hidrográfica e planejamento regional.

\section{Referências bibliográficas}

CHRISTOFOLETTI, A. Geomorfologia. São Paulo: Edgard Blücher, Ed. da Universidade de São Paulo, 1974. 149p.

IPT. Mapeamento Geomorfológico do Estado de São Paulo. São Paulo. Escala 1:500.000. 130p. 2v. (IPT - Publicação, 1183) 1981.

SCHERER, C.; FACCINI, U. \& LAVINA, E. Arcabouço Estratigráfico do Mesozóico da Bacia do Paraná. In: Geologia do Rio Grande do Sul. Porto Alegre: Editora da Universidade UFRGS, 2002. p. 335-354.

SOUTO, R. Deserto: Uma Ameaça? Secretaria da Agricultura do Rio Grande do Sul, DRNR, Diretoria Geral, Porto Alegre, 1985.

SUERTEGARAY, D.M.A. A Trajetória da Natureza um Estudo Geomorfológico sob os Areais de Quaraí/RS. Tese de Doutorado. USP-FFLCH, 1987

SUERTEGARAY, D.M.A. Deserto Grande do Sul: Controvérsias. Porto Alegre: Ed. da Universidade /UFRGS, 1992. 109p. 
TRENTIN, R. \& ROBAIMA, L.E.S. Determinação de unidades ...

SUERTEGARAY, D. M. A.; GUASSELLI, L. \& VERDUM, R. (org.). Atlas de Arenização: Sudoeste do Rio Grande do Sul. Porto Alegre: Secretaria da Coordenação e Planejamento, 2001. v. 1. Mapas.

TRENTIN, R. e ROBAINA, L. E. S. Metodologia para mapeamento Geoambiental no Oeste do Rio Grande do Sul. In: XI Congresso Brasileiro de Geografia Física Aplicada, 2005, São Paulo. Anais... São Paulo, 2005, p. 3606-3615.

TRENTIN, R e ROBAINA, L. E. S. Unidades Litológicas da Bacia Hidrográfica do Rio Itu, Oeste do Rio Grande do Sul. Ciência e Natura, v. 28, p. 67-84, 2006.

VERDUM, R. L'Approche Pour Comprendre la Dynamique du Milieu Dans Le Secteur de São Francisco de Assis tt Manuel Viana - Etat Du Rio Grande Do Sul - Bresil. Université de Toulouse le Mirail, UTM, França, 1993. Mestrado. 93p.

VERDUM, R. Approche Geographique des Deserts Dans les Communes de Sao Francisco de Assis et Manuel Viana, Etat du Rio Grande do Sul, Bresil. Université de Toulouse le Mirail, UTM, França, 1997. Tese de Doutorado, 211p.

Recebido em novembro de 2007

Aceito em abril de 2008 
